\title{
Study of Mass Transfer Behaviour in a PDMS-FTBA Mixed Oxygen Selective Membrane for Li-air Batteries
}

\author{
Jie Li, Linfa Hou, Lihua Luan, Tianyu Zhang, Hong Sun* \\ School of Mechanical Engineering, Shenyang Jianzhu University, No 25, Hunnan Middle Road, \\ Shenyang, 110168, China. \\ *E-mail: sunhongwxh@sina.com, lijie@sjzu.edu.cn
}

doi: $10.20964 / 2021.07 .03$

Received: 4 March 2021 / Accepted: 27 April 2021 / Published: 31 May 2021

\begin{abstract}
Because they have 10 times the energy density of lithium-ion batteries, Li-air batteries are very promising for application in electric vehicles. In addition to the materials used in the batteries, oxygen filtering and internal oxygen transfer resistance are also key issues that need to be resolved to ensure the application of Li-air batteries. First, in this paper, the molecular dynamics (MD) method and the Monte Carlo (GCMC) method are employed to study the dissolution and diffusion behaviour of oxygen molecules and water molecules in the commonly-used oxygen selective membrane with polydimethylsiloxane (PDMS). To further improve the dissolution and diffusion performance and analyse the mechanism of internal oxygen transfer, a new type of oxygen selective membrane is prepared by mixing polydimethylsiloxane (PDMS) and perfluorotributylamine (FTBA). The results show that in addition to effectively limiting the diffusion behaviour of water molecules, the commonly-used PDMS membrane also reduces the diffusion ability of oxygen molecules. However, the mixed oxygen membrane formed by mixing PDMS and FTBA at a mass ratio of 1:3 improves the diffusion performance of oxygen molecules while limiting the diffusion ability of water molecules, which can enhance the battery performance while filtering oxygen. This study provides technical support for the transition from $\mathrm{Li}-\mathrm{O}_{2}$ batteries to Li-air batteries.
\end{abstract}

Keywords: Li-air battery, oxygen selective membrane, molecules, diffusion

\section{$\underline{\text { FULL TEXT }}$}

(C) 2021 The Authors. Published by ESG (www.electrochemsci.org). This article is an open access article distributed under the terms and conditions of the Creative Commons Attribution license (http://creativecommons.org/licenses/by/4.0/). 